\title{
Reinterpreting the nursing record for an electronic context
}

\section{Nicholas R. Hardikerª, Dawn Dowding ${ }^{\mathrm{b}}$, Patricia C. Dykes ${ }^{\mathrm{c}}$, Walter Sermeus ${ }^{\mathrm{d}}$}

${ }^{a}$ School of Human and Health Sciences, University of Huddersfield, UK. n.hardiker@hud.ac.uk

${ }^{b}$ Division of Nursing, Midwifery and Social Work, School of Health Sciences, University of Manchester, UK. dawn.dowding@manchester.ac.uk

${ }^{c}$ Department of General Internal Medicine and Primary Care, Brigham and Women's Hospital/Harvard Medical School, USA. pdykes@bwh.harvard.edu

${ }^{d}$ Leuven Institute for Healthcare Policy, KU Leuven, Belgium.walter.sermeus@kuleuven.be

\section{Corresponding author}

Professor Nick Hardiker RN PhD FACMI

Associate Dean (Research \& Enterprise)

School of Human and Health Sciences

University of Huddersfield

R1/19, Ramsden Building

Queensgate

Huddersfield

HD1 3DH

UK

Email: n.hardiker@hud.ac.uk 


\begin{abstract}
Background: This article seeks to facilitate the re-imagining of nursing records purposefully within an electronic context. It questions existing approaches to nursing documentation, critically examines existing nursing record systems and identifies new requirements.
\end{abstract}

Methods: A comprehensive literature review was conducted to identify themes, that might meaningfully contribute to a new approach to nursing record systems development, around four key interrelated areas - standards, decision making, abstraction and summarization, and documenting. Studies were analyzed using narrative synthesis to provide a critical analysis of the current 'state of the art', and recommendations for the future.

Results: Included studies collectively described aspects of current best practice, both in terms of nursing record systems themselves, and how nurses and other health professionals contribute to and engage with those systems. A number of cross-cutting themes identified more novel approaches taken by nurses to systems development: going back to basics in determining purpose; firming up informatics foundations; nuancing or tailoring to suit different requirements; and engagement, involvement and participation.

Conclusion: There is a paucity of research that specifically focuses on the nature of the electronic nursing record and its impact on patient care processes and outcomes. In addition to further research in these areas, there is a need: to reinterpret nurses as knowledge workers rather than as 'data collectors'; to agree on the application in practice of appropriate standards and terminologies; and to work together with system developers to change the ways in which data are captured and care is documented.

Keywords: nursing, electronic health record, requirements, terminology, decision support systems, quality indicators, user-computer interface

\section{Introduction}

Nurses form the largest part of the healthcare workforce worldwide; qualified nurses comprise nearly $30 \%$ of the total UK NHS workforce and $55 \%$ of the professional qualified clinical staff employed in the NHS [1]. As part of the wider healthcare workforce, nurses are key to transformational changes in the way care is delivered, with a central role in care coordination $[2,3]$, and in the promotion of self-management of care for patients [4]. The introduction of electronic health record (EHR) systems has long had the potential to support such care transformation, with concurrent improvements in both the quality and safety of care [5, 6].

However, to maximize the benefits of these changes, there needs to be a transformational change in the way in which we conceptualize the role and content of such records. Existing EHR systems fail to fully reflect and support the dynamic, inter-professional and patient-centred nature of nursing practice, and inhibit the optimal use of potentially valuable data.

The aim of this literature review is to evaluate the existing evidence base related to the structure and format of nursing electronic health record systems, with a view to making recommendations for systems in the future.

\section{Background}

There is considerable evidence to indicate that there are certain elements of an EHR, which can lead to improved health care quality and support improvements in patient outcomes. For example, the adoption and use of standards and structures are needed to build evidence from practice and to establish linkages between nursing care and patient outcomes [7]. It has been showed (through a randomized trial) that the accuracy of nursing documentation is significantly better when the EHR is pre-structured [8]. Well-designed systems that are integrated into the clinical workflow can also support clinical practice activities such as communication [9], and handover [10]. Systems which have the ability to track what nurses do can improve care efficiencies and inform potential cost savings related to nursing ratios, care delivery, assignments, and work flow [11]. When clinical decision support (CDS) is built so that it fits into a clinicians' workflow (meaning alerts are integrated into their documentation routines, and are actionable) and provide information and guidance at the point when the decision is being taken, they have more likelihood of improving care processes and subsequent patient outcomes [12].

Systems that promote automatic data capture at the point of care, use the same data for more than one purpose, and are designed to ensure the fit with clinicians' work, are more likely to contribute to high quality patient care. A necessary requirement for such systems is an efficient and effective data infrastructure. In nursing this requires a paradigm shift, focusing not on nursing concepts and theories but the nature of nurses' work as the guiding principle [13]. A major obstacle associated with existing EHR systems is that they were largely developed independently of workflow and without the input of nurses and other end-users [14-16].

Almost all existing EHR systems have been developed using an approach to documentation of healthcare that has been adapted from a 'written world' and normally consist of modules such as computerized physician order entry (CPOE), medication prescribing and administration, doctors notes, nursing notes and other elements (such as laboratory reporting and computerized decision support). As a consequence, users of EHR systems highlight problems with finding information, duplication of information, inadequate system functionality, and EHR systems that do not fit with workflow; This inevitably leads to augmentations or 'workarounds'[17-22].

The 'silo' nature of existing systems is a fundamental challenge for nurses in that they inhibit inter-disciplinary and patient-centred care. There are many other fields, from banking to radiography, where the introduction of electronic systems has resulted in additional and significant improvements both in the way that people do their jobs, and in terms of the outcomes of their actions. However, research exploring how EHR systems effect the work of nursing has highlighted how the systems do not fit with nurses' work, often leading to either a lack of timely documentation of care, or an increased burden on nurses' time [13, 23-27]. Moreover, even a Cochrane review of nursing record systems was unable to demonstrate that a change in record systems can contribute to significant improvements in nursing practice or health outcomes [28]. This brings into question the architecture or foundations upon which nursing documentation is built.

A new specification is needed to reveal the full potential of the EHR in helping to improve the quality, safety and efficiency of healthcare. While our study is applicable to other health disciplines, our focus is on the nursing record, given a) nurses are the largest part of the healthcare workforce b) historically 
their requirements for health care documentation have been largely ignored by developers of EHR systems [26] and c) the silo nature of nursing documentation, as already highlighted, is a barrier to interdisciplinary collaboration and patient-centered care.

Central to our approach is the recognition that:

- $\quad$ there should be no distinction between primary and secondary uses of health care data (in that being able to extract data and use it for decision support or reporting functions is as important as using it as a record of care)

- healthcare is inter-professional, and therefore while it is important that we can identify who has provided care to a patient (such as a nurse, physician or physical therapist), this should not necessitate a separate set of notes for each profession in the patient record. Rather, the record should be patient-centred.

In this study we address four research questions (that in turn align with four key functional areas representing, supporting, reporting and recording):

1. Standards. What type of data infrastructure (e.g. clinical standards, standardised terminologies, record architectures, messaging formats) are required to support nursing practice in a patient-centred interdisciplinary team?

2. Decision making. What factors need to be incorporated into an EHR to support nurse decision making at the point of care?

3. Abstraction and summarisation. What factors need to be incorporated into an EHR to enable the abstraction and summarisation of nursing practice data to provide information for patient monitoring and evaluation?

4. Documenting. What is the best way of documenting nursing practice to support clinical care and self-care management for patients?

The literature review described in this article lays the foundations for a fundamental rethink of nursing records. It is not simply a call to arms; nor is it yet another review of what works and what doesn't work [28]. Instead we use a rigorous approach to critically examine existing functionality and to explore new requirements for nursing records. We question the existing paradigm, with its literal interpretation of existing paper-based artefacts into digitized metaphors. And finally, we seek to facilitate the re-imagining of nursing records purposefully within an electronic context.

\section{Methods}

The purpose of the literature review was to map the existing evidence base for each of the four research questions identified above, as well as to identify research that explores the nature of nurses' work, and how EHRs have either facilitated or hindered that work. We were interested particularly in eliciting a new set of requirements for nursing records rather than demonstrating, as other have done, any impact of existing records on nurse behaviors, patient outcomes, resource utilization, etc. Thus the literature review could be framed as a scoping study. The focus of a scoping study is to identify all relevant literature, regardless of the study design [29]. This approach to reviewing the literature is iterative in nature, beginning with broad definitions of the research area, which is refined and revisited as the review progresses. The following process was followed:
Stage 1: Identifying the research question

The purpose of this stage was to revise and define the parameters for the initial search of the literature, based on the main focus of the four research questions: standards, decision making, abstraction and summarization, and documenting. The focus was on the identification of a broad coverage of existing research.

\section{Stage 2: Identifying relevant studies}

We were comprehensive in identifying published studies in the field of interest. We searched for potentially relevant studies via the electronic databases Medline and CINAHL. As agreed across the project team and based on the results of a series of trial searches we used four proxy indexing terms to access records relating to each of the research questions, as presented in Table 1, combined (AND) with Nursing for MEDLINE and Patient Record Systems for CINAHL.

Table 1: Proxy indexing terms used to access records relating to the study research questions.

\begin{tabular}{|l|l|l|}
\hline $\begin{array}{l}\text { Research } \\
\text { question focus }\end{array}$ & $\begin{array}{l}\text { MEDLINE key- } \\
\text { word }\end{array}$ & $\begin{array}{l}\text { CINAHL key- } \\
\text { word }\end{array}$ \\
\hline Standards & $\begin{array}{l}\text { Terminology as } \\
\text { Topic }\end{array}$ & Nomenclature \\
\hline $\begin{array}{l}\text { Decision mak- } \\
\text { ing }\end{array}$ & $\begin{array}{l}\text { Decision Support } \\
\text { Systems, Clinical }\end{array}$ & $\begin{array}{l}\text { Decision Support } \\
\text { Systems, Clinical }\end{array}$ \\
\hline $\begin{array}{l}\text { Abstraction } \\
\text { and summari- } \\
\text { zation }\end{array}$ & $\begin{array}{l}\text { Quality Indicators, } \\
\text { Healthcare }\end{array}$ & Clinical Indicators \\
\hline Documenting & $\begin{array}{l}\text { User-Computer In- } \\
\text { terface }\end{array}$ & $\begin{array}{l}\text { User-Computer } \\
\text { Interface }\end{array}$ \\
\hline
\end{tabular}

Given the relative newness of most EHR systems, and the rapidly changing nature of technology, we limited our search to the dates 2012 - August 2018. We acknowledge that this time limit may have excluded some potentially relevant historical studies. However, this approach means that we were able to identify the most recent and relevant research evidence for our purposes.

\section{Stage 3: Study Selection}

The inclusion criteria for the review were constructed after the initial search had been completed, in line with [29], and then applied to all citations independently by two reviewers. Studies were deemed eligible for inclusion if they were written in English, described a degree of practical application and could contribute in some way to nursing information systems requirements gathering.

We retrieved the full text of all articles that met our inclusion criteria (and addressed one of the four research questions), and then decided on whether or not the study was suitable for inclusion in the review.

\section{Stage 4: Charting the data}

To further guard against selection bias, two members of the project team independently extracted data from the included reviews using a standard data extraction form.

Using a 'narrative review' approach data from included studies were synthesized, key themes were identified and findings summarized.

Stage 5: Collating, Summarizing and Reporting the Results The results of each of the sub-reviews were collated, synthesized and summarized, to provide an overview of current evidence regarding 
a) how EHR systems currently support/do not support nurses' work

b) the recommended data infrastructure for an effective EHR system

c) components of a system that should be built in to support decision making at the point of care, reporting of nursing practice for policy and management purposes, supporting clinical care and patient self-care.

Although not of principle concern given the overall aims of the work, the quality of the included studies was assessed by drawing on the key questions presented in the HCPRDU evaluation tool for quantitative studies [30].

As this was a review of published literature, ethical approval was not required for this study.

\section{Results}

The literature search was completed in September 2018. The indexing terms used determined the scope of the search. For

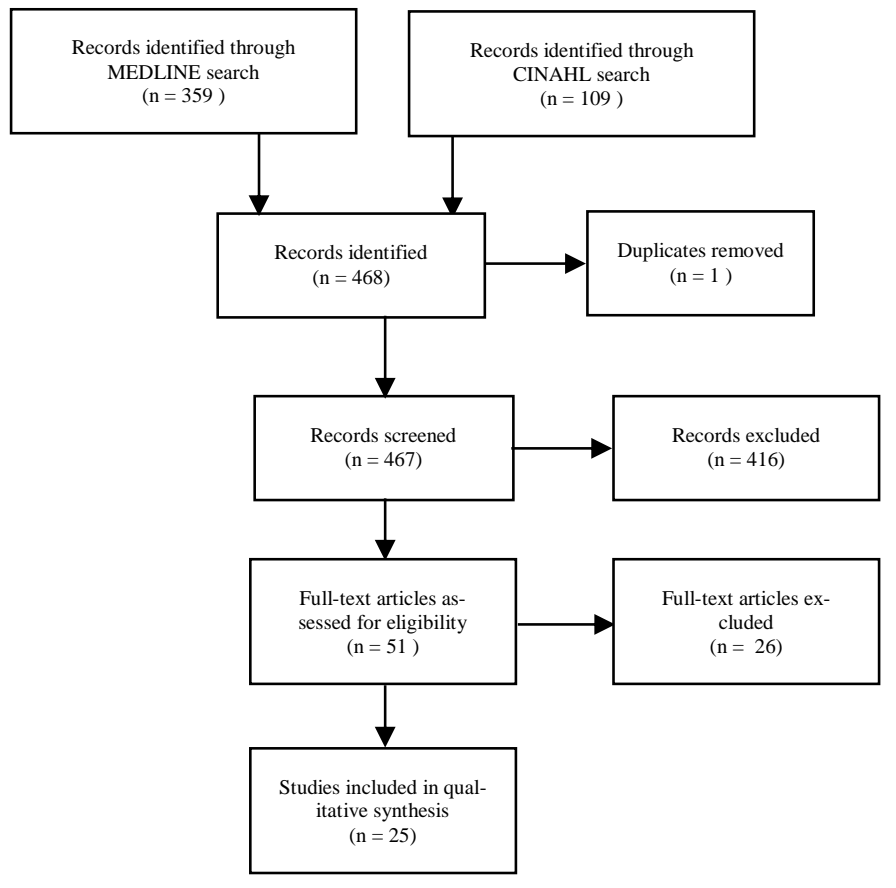

Figure 1: PRISMA flowchart summarizing filtering of articles

example, for Abstraction and Summarization, the emphasis was on the reuse of clinical data in the development of indicators to support quality management, rather than other activities such as research. The emphasis on nursing also ruled out more widely-published issues with EHRs, such as alert fatigue and false positive automated alerts (for Decision making). A PRISMA flowchart summarizes the filtering in Figure 1. The search identified 468 records, with a much higher proportion $(77 \%)$ through Medline. Of the original total number of records, $89 \%(\mathrm{n}=416)$ were excluded through initial screening and the removal of duplicates $(n=1)$ and a further $6 \%(n=26)$ were excluded through eligibility testing. The inclusion criteria served to bound the scope of the search. For example, for Standards, the need for a degree of practical application ruled out articles describing the development and in vitro testing of terminologies. Reasons for rejection after eligibility testing included: out of scope $(n=14)$; opinion piece $(n=4)$; descriptive piece with no consideration of practical application $(\mathrm{n}=$ $5)$; immature work with no results presented $(n=2)$; insufficient information $(n=1)$. Table 2 provides a breakdown of search results and included articles by research question topic.A total of 25 articles were included in the review.

Over half of the included studies $(n=13)$ were conducted in the USA, with 4 conducted in the Netherlands, 3 in Canada and 1 each in Argentina, Singapore and Taiwan. Two literature reviews were international in nature (but conducted in the USA).

Table 2: Breakdown of search results and included articles, by research question topic

\begin{tabular}{|l|l|l|l|l|}
\hline $\begin{array}{l}\text { Re- } \\
\text { search } \\
\text { question } \\
\text { focus }\end{array}$ & $\begin{array}{l}\text { Re- } \\
\text { trieved } \\
\text { via } \\
\text { Medline }\end{array}$ & $\begin{array}{l}\text { Re- } \\
\text { trieved } \\
\text { via Ci- } \\
\text { nahl }\end{array}$ & $\begin{array}{l}\text { Included } \\
\text { after ini- } \\
\text { tial } \\
\text { screening }\end{array}$ & $\begin{array}{l}\text { Included } \\
\text { after eli- } \\
\text { gibility } \\
\text { testing }\end{array}$ \\
\hline $\begin{array}{l}\text { Stand- } \\
\text { ards }\end{array}$ & 134 & 8 & 4 & 3 \\
\hline $\begin{array}{l}\text { Decision } \\
\text { making }\end{array}$ & 26 & 37 & 16 & 9 \\
\hline $\begin{array}{l}\text { Abstrac- } \\
\text { tion and } \\
\text { summari- } \\
\text { zation }\end{array}$ & 127 & 34 & 12 & 5 \\
\hline $\begin{array}{l}\text { Docu- } \\
\text { menting }\end{array}$ & 72 & 30 & 19 & 8 \\
\hline Total & $\mathbf{3 5 9}$ & $\mathbf{1 0 9}$ & $\mathbf{5 1}$ & $\mathbf{2 5}$ \\
\hline
\end{tabular}

The goal of this review was to elicit factors that might inform a reinterpretation of the nursing record for electronic systems; and replicability was not of primary concern. However, the nature and quality of the included studies may provide important context. The majority of studies $(n=21)$ were descriptive in nature; of the 5 empirical studies (one of these was a mixed-methods study) none appeared to apply any form of control. All included studies were fundamentally qualitative in nature, employing a range of techniques to facilitate validation, consensus building, textual analysis, secondary data analysis, elicitation of opinion, etc. The quality of the included studies was variable: 15 were considered to be of good quality, 4 fair and 6 poor.

Several important themes emerged from the literature. For convenience, these are presented below by research question focus.

\section{Standards}

A report of a study carried out in a Magnet facility in the USA describing the development of a patient centric record argued that care is a broad term that covers both basic care activities and more goal-directed care activities [31]. It also argued that as documentation is used primarily to facilitate communication about care, documentation that does not relate to care, whether basic or goal-directed, should be minimized (although this may be counterproductive in the context of Abstraction and summarization - see below). It should be noted that the authors felt that observation and intervention statements that might be used within documentation should be derived not solely from practice or care, but also from theory and regulatory requirements.

A descriptive Doctoral study also conducted in the USA explored documentation relating to care in seeking to identify retrospectively from a range of sources the characteristics of cancer patients and the most commonly-selected nursing diagnoses, interventions and outcomes [32]. The study found commonality in the selection of observation and intervention statements, and in linkages between these, although the most com- 
mon observation and intervention statements may vary between settings. The study also posited that structured documentation, with standardized language and support for critical reasoning and decision-making can guide practice and facilitate evaluation of care.

A retrospective, mixed-methods observational study carried out in an ICU setting in Canada called for the development of a 'lexicon of pain assessment descriptors' to improve documentation, while also arguing that narrative notes are useful in nuancing observations and interventions argued for greater consistency in the use of language [33].

\section{Decision making}

While studies suggest that the capture of observation and intervention statements can be facilitated using standardized terminologies, according to the authors of a retrospective analysis of secondary intensive care unit data conducted in the USA, any redesign of EHRs to fit with workflow might require changes in the way nurses document [34]. Studies have indicated that CDS can support the nursing process [35], and improve patient flow through the health system [36]. The studies supporting these points include a structured review of peer reviewed literature describing primary studies on decision support systems for nursing practice [35] and an Argentinian conference report comparing an 'eTriage' system with a manual approach [36].

According to the authors of an empirical study conducted in the USA and with a focus on peripheral nerve injury in the operating room, CDSS may also serve to improve documentation [37]. However, according to the authors of a qualitative study conducted in Singapore to explore decision support around wound care, there are several issues that influence the adoption of CDSS, including ease of use, trust, culture and fit with practice [38]; although a Dutch mixed methods evaluation of a system to support decisions around patient assignment indicated that the pre-population of data fields may actually improve workflow [39]. A focus group study conducted in the USA found that lack of fit with the context of use, including mandated use of CDSS, may lead to frustration and workarounds [40]. It appears to be important that evidence is presented in a way that helps users see benefits to patients and helps them weigh its applicability within a particular circumstance. Acceptance appears to depend on a belief on the part of the user that suggestions are good for the patient (i.e. trust) and on system features that provide secondary reinforcement. The reasons for non-acceptance appear to be more complex but a simulation study in the USA suggests that it may hinge on disagreement or lack of confidence in the displayed information [41]. While it appears that decision support algorithms can help individuals without expertise make good decisions, as demonstrated in a mixed methods construct validation, also in the USA, of an algorithm to support ostomy product choices [42], there is also a recognition that CDSS cannot completely replace human judgement [39].

\section{Abstraction and summarization}

In a description of a European study exploring the development of quality indicators relating to breast cancer care, the authors explained how useful data abstractions are situated in a cultural context and it is important to consider how the structure of an EHR might facilitate (or hinder) appropriate data collection [43]. In the context of midwifery care, the authors of a Dutch consensus study recommended that linkages should be made between higher-level abstractions, such as quality indicators, and patient-level data [44]. A relatively small-scale $(n=94)$ descriptive study of post-partum hemorrhage in a primary care setting in the Netherlands concluded that it may be possible to derive meaningful and useful indicators from routinely collected data [45]. Two consensus projects, one with a focus also on post-partum hemorrhage in Dutch primary care, and a second with a focus on hospice and palliative care in the USA, independently argued that it may also be possible to use potential indicators (where patient-level data might not be available) to inform the development of EHRs [46, 47].

\section{Documenting}

Several studies revealed usability issues including: navigation, general ease of use and time to complete tasks [48]; complexity of data entry processes [49]; and, duplication of information, poor fit with workflow, low trustworthiness of information presented and a need for training [50]. The studies supporting these points include a Canadian mixed-methods study exploring point-of-care access to information [48], a survey conducted in Taiwan exploring the impact of use of a webbased incident reporting system [49] and a study exploring attitudes to EHR alerts [50]. While these negative system characteristics point towards more positive solutions such as tailorable displays that can overcome some of the limitations of generalized solutions as found in a study evaluating clinical data interpretation by intensive care unit nurses in the USA [51], it is discouraging that after several decades of research, development, implementation and use, these familiar issues persist. However, there appear to have been some advances, for example: 1) around the use of real-time feedback a) to improve documentation itself [52], and b) to monitor performance relating to patient outcomes and experiences [53]; 2) around the need for simplicity in design to improve the speed and accuracy of clinical decisions [54]; and 3) around the benefits and drawbacks of structured, unstructured and semistructured data entry, including impact on data quality [55]. The studies supporting these points include a Canadian qualitative study [53], and a study conducted in an emergency setting [52], a laboratory-based usability study[54] and a recent literature review [55], all conducted in the USA.

\section{Discussion}

The combination of a relatively broad search strategy with targeted inclusion criteria revealed a number of relevant and useful sources for this the review. There was sufficient depth of content across the included studies point to possible enhancements to current practice and to urge new thinking about the nature of EHR system components, about ways of working, and about nursing practice itself. This study makes no apologies for the variable strength of evidence across the studies. The study never sought to establish any cause-effect relationships but merely to inform discussions around nursing records, thereby provoking a shift in thinking. Critical analysis of the synthesized findings across all four focus areas provides a useful starting point for these discussions. There are several major themes running across the four areas:

1. a need to go back to basics in determining purpose;

2. a need to firm up informatics foundations;

3 . a need for nuancing or tailoring to suit different requirements; and

4. a need for nurses to get engaged in debates and involved in developments.

Standards provide the foundations for robust nursing record systems and there are indications that there has been an element of monotheism in the purpose and role of standards. For example, it would be possible to develop standardized terminologies in order separately to reify nursing theory, to satisfy regulatory requirements or to meet the requirements of clinical 
practice. In practice, terminologies need to meet all of these needs while also providing data to derive meaningful indicators. Advances in terminologies mean that we can capture in an agreed representation format many more facets of nursing practice than ever before. While a comprehensive account is in itself a good thing, there is a risk of being seduced into a justin-case position of 'because it can be coded, it should be coded'. An already over packed information space requires us to look not just at post-hoc usability issues but to consider prehoc the data we are seeking to collect, and reach consensus on the minimum data (including how, where and when it is collected) necessary to inform practice, as well as for other data uses. We may also need to rethink nursing practice itself to separate basic care (i.e. what patients can reasonable expect as a default) from goal-directed activities. In addition, any restrictions in the coding space will necessitate, at least for the purposes of direct care, efficient systems to capture annotations (unstructured notes). This importance of narrative description for enabling more nuanced decision making is highlighted across several included studies; the ability to 'paint a picture' over time [56] of a patient's care trajectory is an important dimension that is currently not consistently captured in contemporary EHR systems.

Agreement on the standards to be used, and the data to be collected at the point of care, is a precondition for ensuring effective decision support, and the reuse of data for quality of care indicators. Further research to focus on the types of cognitive support health professionals require [57], including the use of participatory design approaches [56] will help to ensure systems are fully integrated with nurse workflow. Identifying what decisions need to be supported and for whom (based on user characteristics such as expertise), may also ensure better tailoring of CDS interventions (moving away from a proliferation of alerts) and a tighter focus on safety and quality-critical issues (such as prescribing). In addition, there is a need for a better understanding of the interrelationship between decision making and workflow. Systems should be built around how individuals think and work (rather than around traditional paper-based metaphors), synthesizing and summarizing information from numerous sources to meet the needs of clinicians and presenting it in a digestible form where and when it is needed i.e. at the point of decision making [58].

A recent review of how data is structured for a range of uses (such as for quality improvement initiatives) highlighted that currently most data structuring occurs post hoc, rather than at the point of care [59]. However, information quality is better and clinical data more complete when data structuring occurs at the point of care. Future EHR designs need to ensure that patient level data can be appropriately summarized and aggregated into meaningful quality indicators, without additional data entry. In order to effect this, nurses need to engage with classification science to elevate understanding, and EHR structures should be nuanced to practically support it. There appears to be a global shift in interest away from process (i.e. planned input) and towards outcome, both on individual and aggregate level [60], where reimbursement is made not only for volume but also for quality of care (i.e. value-based healthcare). There is a commensurate need to extend the use of EHRs beyond documenting care towards helping to reach the quadruple aim of improving population health, improving patient experience, reducing costs, and improving the experience of providing care (decreasing documentation burden is one component of achieving that aim)[61]. The nature of indicators is evolving to mirror these paradigmatic changes. For example, in 2017 the Hospital Value-Based Purchasing (VBP) Program replaced $2 \%$ of traditional case-mix based payments with payments based on quality indicators such as Patient and Caregiver Centered Experience of Care/Care Coordination
[62]. Indicators to help manage nursing care need also to keep pace with these changes.

With changes to the way in which patient information is documented, emphasizing the collection of structured (and automatically coded) information about a patient and their care process at the point of care, there will be a need for changes to the way in which data are captured. Acknowledging this, and building systems that are tailored to users' requirements, and built for usability (such as quick and efficient data capture at the point of care rather than mimicking a paper-based system where care is documented at a later time point), is imperative for EHR system design going forward. Currently there is considerable variability in how EHR systems are built, with potential consequences for patient safety[63]. Designing systems that can provide tailored feedback to clinicians, using data displays and visualization techniques [56] have the potential to both provide an incentive for accurate and timely data documentation, and provide the type of cognitive support clinicians need to make patient care decisions.

\section{Conclusion}

The aim of this review was to evaluate the existing evidence base relating to the structure and format of the nursing component of EHRs, with a view to making recommendations for systems in the future. The review highlighted the paucity of research that specifically focuses on the nature of the electronic nursing record and its impact on patient care processes and outcomes. There are a number of robust technical standards and terminologies for nursing. However, what is apparent is the need to consider how those standards should be applied. We also need to recognize that electronic systems need to balance the collection of structured and coded data with narrative data that provides a more nuanced insight into patient care. The accurate and reliable capture of patient data is a pre-requisite for ensuring appropriate decision support for nursing practice, and for ensuring that data can be used in aggregate for other purposes such as quality monitoring. We need to move away from nurses as 'data collectors', and to think of them as knowledge workers [64], focusing on what information is necessary to inform patient care, and ensuring systems are built to collect, transform and feedback that information in a way that supports decision making in practice, for example through the intelligent reuse of clinical data. System developers need to continue to work with nurses to ensure that systems are both usable and useful.

\section{Authors' contributions}

NRH, DD, PCD and WS contributed to the design and implementation of the research, to the analysis of the results and to the writing of the manuscript.

\section{Statement on conflicts of interest}

The authors have no conflicts of interest to declare

\section{Summary table}

What was already known on this topic?

- Electronic health records (EHR) have the potential to facilitate positive transformation of health care 
- Existing EHRs fail to reflect and support the dynamic, inter-professional and patient-centred nature of health care, and inhibit the optimal use of data

- There needs to be a fundamental rethink of the way in which we conceptualize the role and content of EHRs

What this study added to our knowledge?

- There is lack of consensus on the minimum data (including how, where and when it is collected) necessary to inform practice, as well as for other data uses

- There is a lack of understanding about how patient level data should be summarized and aggregated into meaningful quality indicators

- Our knowledge of the types of cognitive support health professionals require for decision making is suboptimal

- There is a poor fit between EHR systems and how individuals think and work at the point of decision making

- By encouraging uniformity without managed flexibility, existing EHR systems may actually encourage unwanted variability in application

\section{References}

1. Health and Social Care Information Centre. NHS Workforce Statistics - March 2014 Provisional Statistics England: Health and Social Care Information Centre; 2014 [Available from:

http://www.hscic.gov.uk/searchcatalogue?productid=14868\&t opics $=1 \% 2 \mathrm{fW}$ orkforce $\% 2 \mathrm{fStaff}+$ numbers \&sort=Relevance \&s ize $=10$ \&page $=1 \#$ top .

2. Francis R. Report of the Mid Staffordshire NHS

Foundation Trust Public Inquiry. London, UK: The Stationary Office; 2013.

3. American Nurses Association. The Value of Nursing Care Coordination. In: Association AN, editor. Silver Spring, MD2012.

4. Davies N. Improving self management for patients with long-term conditions. Nursing Standard. 2010;24(25):4956.

5. Silow-Carroll S, Edwards J, Rodin D. Using electronic health records to improve quality and efficiency: the experiences of leading hospitals. New York: The Commonwealth Fund; 2012.

6. Kutney-Lee A, Kelly D. The effect of hospital electronic health record adoption on nurse-assessed quality of care and patient safety. Journal of Nursing Administration. 2011;41(11):466-72.

7. Dykes P, Collins S. Building Linkages between Nursing Care and Improved Patient Outcomes: The Role of Health Information Technology. Online Journal of Issues in Nursing. 2013;18(3).

8. Paans W, Sermeus W, Nieweg RM, Krijnen WP, van der Schans CP. Do knowledge, knowledge sources and reasoning skills affect the accuracy of nursing diagnoses? a randomised study. BMC nursing. 2012;11:11.

9. Motamedi S, Posadas-Calleja J, Straus S, Bates D, Lorenzetti D, Baylis B, et al. The efficacy of computer- enabled discharge communication interventions: a systematic review. BMJ Qual Saf. 2011;20(5):403-15.

10. Starmer AJ, Sectish TC, Simon DW, Keohane C, McSweeney ME, Chung EY, et al. Rates of medical errors and preventable adverse events among hospitalized children following implementation of a resident handoff bundle. JAMA : the journal of the American Medical Association.

2013;310(21):2262-70.

11. Reeder S, Toor P. Radio Frequency Identification Device (RFID) and Real Time Location Systems (RTLS) Enhance Nursing Care Delivery. Sigma Theta Tau International 24th International Nursing Research Congress; Hong Kong2014.

12. Kawamoto K, Houlihan C, Balas E, Flobach D. Improving clinical practice using clinical decision support systems: a systematic review of trials to identify features critical to success. BMJ. 2005;330:765.

13. Goorman Els, Berg Marc. Modelling nursing activities: electronic patient records and their discontents. Nursing Inquiry. 2000;7:3-9.

14. Kossman S, Bonney L, Kim M. Electronic health record tools' support of nurses' clinical judgment and team communication. Computers Informatics Nursing.

2013;31(11):539-44.

15. Yu P, Zhang Y, Gong Y, Zhang J. Unintended adverse consequences of introducing electronic health records in residential aged care homes. International journal of medical informatics. 2013;82(9):772-88.

16. Rogers ML, Sockolow PS, Bowles KH, Hand KE, George J. Use of a human factors approach to uncover informatics needs of nurses in documentation of care. International journal of medical informatics.

2013;82(11):1068-74.

17. Bloomrosen M, Starren J, Lorenzi NM, Ash J, Patel VL, Shortliffe EH. Anticipating and addressing the unintended consequences of health IT and policy: a report from the AMIA 2009 Health Policy Meeting. Journal of the American Medical Informatics Association. 2011;18:82-90.

18. Campbell E, Sittig DF, Ash JS, Guappone K, Dykstra RH. Types of Unintended Consequences Related to Computerized Provider Order Entry. Journal of the American Medical Informatics Association. 2006;13(5):547-56.

19. Harrison MI, Koppel R, Bar-Lev S. Unintended consequences of information technologies in health care - An interactive sociotechnical analysis. Journal of the American Medical Informatics Association. 2007;14(5):542-9.

20. Collins SA, Fred MR, Wilcox L, Vawdrey DK. Workarounds Used by Nurses to Overcome Design Constraints of Electronic Health Records. 11th International Congress on Nursing Informatics; June 23-27; Montreal, Canada2012.

21. Koppel R, Wetterneck TB, Telles JL, Karsh B-T. Workarounds to Barcode Medication Administration Systems: Their Occurrences, Causes, and Threats to Patient Safety. Journal of the American Medical Informatics Association. 2008; 15:408-23.

22. Dowding DW, Turley M, Garrido T. Nurses' use of an integrated electronic health record: results of a case site analysis. Informatics for Health and Social Care. 2015;40(4):345-61.

23. Carrington JM, Effken JA. Strengths and limitations of the electronic health record for documenting clinical events. CIN: Computers, Informatics, Nursing. 2011;29(6):360-7. 24. Reuss E, Keller R, Naef R, Hunziker S, Furler L. Nurses' working practices: What can we learn for designing computerised patient record systems? In: Holzinger A, editor. Hci and Usability for Medicine and Health Care, Proceedings. Lecture Notes in Computer Science. 47992007. p. 55-68. 
25. Staggers N, Clark L, Blaz JW, Kapsandoy S. Why patient summaries in electronic health records do not provide the cognitive support necessary for nurses' handoffs on medical and surgical units: insights from interviews and observations. Health Informatics Journal. 2011;17(3):209-23. 26. Stevenson JE, Nilsson GC, Petersson GI, Johansson PE. Nurses' experience of using electronic patient records in everyday practice in acute/inpatient ward settings: A literature review. Health Informatics Journal. 2010;16(1):63-72.

27. Wolf LD, Potter P, Sledge JA, Boxerman SB, Grayson D, Evanoff B. Describing nurses' work: Combining quantitative and qualitative analysis. Human Factors. 2006;48(1):5-14.

28. Urquhart C, Currell R, Grant MJ, Hardiker NR. Nursing record systems: effects on nursing practice and health care outcomes. Cochrane Database of Systematic Reviews. 2009(1).

29. Arksey H, O'Malley L. Scoping studies: Towards a methodological framework. International Journal of Social Research Methodology. 2005;8(1):19-32.

30. Long A, Godfrey M, Randall T, Brettle A, Grant M. HCPRDU evaluation tool for qualitative studies. Leeds: Nuffield Institute for Health, University of Leeds 2002.

31. Englebright J, Aldrich K, Taylor CR. Defining and Incorporating Basic Nursing Care Actions Into the Electronic Health Record. Journal of Nursing Scholarship.

2014;46(1):50-7.

32. Tseng H-C. Use of standardized nursing terminologies in electronic health records for oncology care: the impact of NANDA-I, NOC, and NIC

Iowa: University of Iowa; 2012.

33. Haslam L, Dale C, Knechtel L, Rose L. Pain descriptors for critically ill patients unable to self-report. Journal of Advanced Nursing. 2012;68(5):1082-9.

34. Byrne MD, Lang N. Examination of Nursing Data Elements From Evidence-Based Recommendations for Clinical Decision Support. CIN: Computers, Informatics, Nursing. 2013;31(12):605-14.

35. Lee S. Features of Computerized Clinical Decision Support Systems Supportive of Nursing Practice: A Literature Review. CIN: Computers, Informatics, Nursing. 2013;31(10):477-95.

36. Mandirola Brieux HF, Guillen S, La Rosa F, Moreno C, Benitez S. Nursing Software for Emergency Triage (NSET). In: Sarkar IN, editor. MEDINFO 2015: eHealthenabled Health. Studies in Health Technology and Informatics. 216. eBook: IOS Press; 2015. p. 942.

37. Bouyer-Ferullo S, Androwich IM, Dykes PC. Clinical Decision Support and Perioperative Peripheral Nerve Injury: A Quality Improvement Project. CIN: Computers, Informatics, Nursing. 2015;33(6):238-48.

38. Khong PCB, Hoi SY, Holroyd E, Wang W. Nurses' Clinical Decision Making on Adopting a Wound Clinical Decision Support System. CIN: Computers, Informatics, Nursing. 2015;33(7):295-305.

39. Van Oostveen CJ, Braaksma A, Vermeulen H. Developing and Testing a Computerized Decision Support System for Nurse-to-Patient Assignment: A Multimethod Study. CIN: Computers, Informatics, Nursing. 2014;32(6):276-85.

40. Moore An, Fisher K. Healthcare Information Technology and Medical-Surgical Nurses: The Emergence of a New Care Partnership. CIN: Computers, Informatics, Nursing. 2012;30(3):157-63.

41. Sousa VEC, Lopez KD, Febretti A, Stifter J, Yao Y, Johnson A, et al. Use of Simulation to Study Nurses'

Acceptance and Nonacceptance of Clinical Decision Support
Suggestions. CIN: Computers, Informatics, Nursing. 2015;33(10):465-72.

42. Beitz JM, Gerlach MA, Schafer V. Construct Validation of an Interactive Digital Algorithm for Ostomy Care. Journal of Wound Ostomy \& Continence Nursing. 2014;41(1):49-54.

43. Fessele K, Yendro S, Mallory G. Setting the bar: developing quality measures and education programs to define evidence-based, patientcentered, high-quality care. Clinical Journal of Oncology Nursing. 2014;18 Suppl(5):7-11. 44. de Bruin-Kooistra M, Amelink-Verburg MP, Buitendijk SE, Westert GP. Finding the right indicators for assessing quality midwifery care. International Journal for Quality in Health Care. 2012;24(3):301-10.

45. Smit M, Chan K-LL, Middeldorp JM, van Roosmalen J. Postpartum haemorrhage in midwifery care in the Netherlands: validation of quality indicators for midwifery guidelines. BMC Pregnancy and Childbirth. 2014;14:397. 46. Dy SM, Kiley KB, Ast K, Lupu D, Norton SA, McMillan SC, et al. Measuring What Matters: Top-Ranked Quality Indicators for Hospice and Palliative Care From the American Academy of Hospice and Palliative Medicine and Hospice and Palliative Nurses Association. Journal of Pain and Symptom Management. 2015;49(4):773-81.

47. Smit M, Sindram SI, Woiski M, Middeldorp JM, van Roosmalen J. The development of quality indicators for the prevention and management of postpartum haemorrhage in primary midwifery care in the Netherlands. BMC Pregnancy and Childbirth. 2013;13(1):194.

48. Di Pietro TL, Nguyen HA, Doran DM. Usability Evaluation: Results From "Evaluation of Mobile Information Technology to Improve Nurses' Access to and Use of Research Evidence". CIN: Computers, Informatics, Nursing. 2012;30(8):440-8.

49. Kuo Y-H, Lee T-T, Mills ME, Lin K-C. The Evaluation of a Web-Based Incident Reporting System. CIN: Computers, Informatics, Nursing. 2012;30(7):386-94.

50. Sidebottom AC, Collins B, Winden TJ, Knutson A,

Britt HR. Reactions of Nurses to the Use of Electronic Health Record Alert Features in an Inpatient Setting. CIN:

Computers, Informatics, Nursing. 2012;30(4):218-26.

51. Drews FA, Doig A. Evaluation of a Configural Vital Signs Display for Intensive Care Unit Nurses. Human Factors. 2013;56(3):569-80.

52. Nielsen G, Peschel L, Burgess A. Essential Documentation Elements: Quality Tool for the Emergency Department Nurse. Advanced Emergency Nursing Journal. 2014;36(2):199-205.

53. Jeffs L, Beswick S, Lo J, Lai Y, Chhun A, Campbell $\mathrm{H}$. Insights from staff nurses and managers on unit-specific nursing performance dashboards: a qualitative study. BMJ Quality \& Safety. 2014;23(12):1001-6.

54. Schall MCJ, Cullen L, Pennathur P, Chen H, Burrell $\mathrm{K}$, Matthews G. Usability Evaluation and Implementation of a Health Information Technology Dashboard of Evidence-Based Quality Indicators. CIN: Computers, Informatics, Nursing. 2017;35(6):281-8.

55. Wilbanks BA, Moss J. Evidence-Based Guidelines for Interface Design for Data Entry in Electronic Health Records. CIN: Computers, Informatics, Nursing. 2018;36(1):35-44.

56. Jeffery AD, Novak LL, Kennedy B, Dietrich MS, Mion LC. Participatory design of probability-based decision support tools for in-hospital nurses. Journal of the American Medical Informatics Association. 2017;24(6):1102-10. 57. Furniss SK, Burton MM, Grando A, Larson DW, Kaufman DR. Integrating Process Mining and Cognitive 
Analysis to Study EHR Workflow. AMIA Annual Symposium Proceedings. 2016;2016:580-9.

58. Clarke A, Adamson J, Watt I, Sheard L, Cairns P, Wright J. The impact of electronic records on patient safety: a qualitative study. BMC Medical Informatics and Decision Making. 2016;16(1):62.

59. Vuokko R, Mäkelä-Bengs P, Hyppönen H, Lindqvist M, Doupi P. Impacts of structuring the electronic health record: Results of a systematic literature review from the perspective of secondary use of patient data. International journal of medical informatics. 2017;97:293-303.

60. Reuben DB, Tinetti ME. Goal-Oriented Patient Care - An Alternative Health Outcomes Paradigm. New England Journal of Medicine. 2012;366(9):777-9.

61. Sikka R, Morath JM, Leape L. The Quadruple Aim: care, health, cost and meaning in work. BMJ Quality \& Safety. 2015;24(10):608-10.

62. The Centers for Medicare \& Medicaid Services. The Hospital Value-Based Purchasing (VBP) Program 2018 [Available from: https://www.cms.gov/Medicare/QualityInitiatives-Patient-Assessment-Instruments/Value-BasedPrograms/HVBP/Hospital-Value-Based-Purchasing.html. 63. Ratwani RM, Savage E, Will A, Arnold R, Khairat S, Miller K, et al. A usability and safety analysis of electronic health records: a multi-center study. Journal of the American Medical Informatics Association. 2018;25(9):1197-201.

64. Courtney KL, Alexander GL, Demiris G. Information technology from novice to expert: implementation implications. Journal of Nursing Management. 2008;16(6):692-9. 